\title{
Predictive value of frailty in the mortality of hospitalized patients with COVID-19: a systematic review and meta-analysis
}

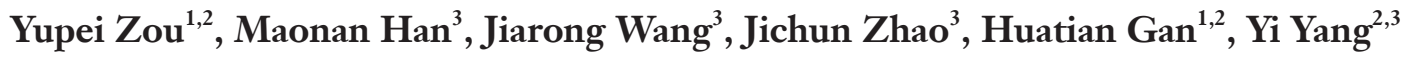 \\ ${ }^{1}$ The Center of Gerontology and Geriatrics, West China Hospital, Sichuan University, Chengdu, China; ${ }^{2}$ National Clinical Research Center for \\ Geriatrics, West China Hospital, Sichuan University, Chengdu, China; ${ }^{3}$ Department of Vascular Surgery, West China Hospital, Sichuan University, \\ Chengdu, China \\ Contributions: (I) Conception and design: Y Yang; (II) Administrative support: H Gan; (III) Provision of study materials or patients: Y Zou, M Han; \\ (IV) Collection and assembly of data: Y Zou, M Han; (V) Data analysis and interpretation: Y Zou, M Han; (VI) Manuscript writing: All authors; (VII) \\ Final approval of manuscript: All authors. \\ Correspondence to: Huatian Gan, MD. The Center of Gerontology and Geriatrics, West China Hospital, Sichuan University, 37 Guo Xue Alley, \\ Chengdu 610041, China. Email: ganhuatian123@163.com; Yi Yang, MD. Department of Vascular Surgery, West China Hospital, Sichuan University, \\ 37 Guo Xue Alley, Chengdu 610041, China. Email: yangy@wchscu.cn.
}

\begin{abstract}
Background: The present study aimed to analyze the impact of frailty on mortality risk among hospitalized patients with coronavirus disease 2019 (COVID-19).

Methods: Literature searches were conducted using the MEDLINE, Embase, and Cochrane databases for articles reporting the association between frailty and mortality in hospitalized patients with COVID-19. The quality of the included studies was assessed using the Newcastle-Ottawa scale (NOS). A random-effects meta-analysis was performed to calculate the pooled effects.

Results: A total of 21 studies with 26,652 hospitalized patients were included. Sixteen studies used the Clinical Frailty Score (CFS), and five used other frailty assessment tools. The pooled estimates of frailty in hospitalized patients with COVID-19 were 51.4\% [95\% confidence interval (CI): 39.9-62.9\%]. In the CFS group, frail patients experienced a higher rate of short-term mortality than non-frail patients [odds ratio $\left.(\mathrm{OR})=3.0 ; 95 \% \mathrm{CI}: 2.3-3.9 ; \mathrm{I}^{2}=72.7 \% ; \mathrm{P}<0.001\right]$. In the other tools group, frail patients had a significantly increased short-term mortality risk compared with non-frail patients (OR =2.4; 95\% CI: 1.4-4.1; $\mathrm{P}=0.001)$. Overall, a higher short-term mortality risk was observed for frail patients than non-frail patients $(\mathrm{OR}=2.8$; 95\% CI: 2.3-3.5; $\mathrm{P}<0.001)$. In older adults, frail patients had a higher rate of short-term mortality than nonfrail patients (OR =2.3; 95\% CI: $1.8-2.9 ; \mathrm{P}<0.001)$.
\end{abstract}

Conclusions: Compared to non-frail hospitalized patients with COVID-19, frail patients suffered a higher risk of all-cause mortality, and this result was also found in the older adult group.

Keywords: Meta-analysis; frailty; mortality; coronavirus disease 2019 (COVID-19)

Submitted Nov 22, 2021. Accepted for publication Feb 14, 2022.

doi: $10.21037 /$ atm-22-274

View this article at: https://dx.doi.org/10.21037/atm-22-274

\section{Introduction}

Since the first reported case of severe acute respiratory syndrome coronavirus 2 (SARS-CoV-2) in China at the end of 2019, coronavirus disease 2019 (COVID-19) has rapidly become a pandemic causing unprecedented health and economic challenges (1). The majority of
COVID-19 patients are asymptomatic or have mild symptoms. However, some individuals develop severe complications leading to death. According to the World Health Organization (WHO) (2), there have been more than four million deaths from COVID-19 across 223 countries as of September 1, 2021. Studies have shown that COVID-19 patients who are elderly and have pre- 
existing comorbidities, such as obesity, hypertension, diabetes, chronic renal insufficiency, or coronary heart disease, have worse clinical outcomes (3).

Frailty is a multidimensional geriatric syndrome characterized by impaired stress tolerance due to a decline in physiological reserves and functioning of different organs and is associated with poor health outcomes, including mortality, admissions to nursing homes, and falls. Frailty is a common syndrome in older individuals (4), with a prevalence rate of $41.3 \%$ in those aged over 65 and $65.2 \%$ in those aged over 80 (5). Nevertheless, aging and frailty are not synonymous (6). Compared with aging, a diagnosis of frailty arises from a comprehensive geriatric assessment that reflects the overall health status of individuals. Several recent studies have explored the association between frailty and the clinical outcomes of patients infected by SARS-CoV-2, but the results remain inconclusive (7-10). Frailty was associated with being female and having comorbidities in patients with COVID-19, and the level of white blood cell count, D-dimer, and C-reactive protein were higher in frail patients $(11,12)$. Most studies have demonstrated that frailty in hospitalized COVID-19 patients is a risk factor for short-term outcomes, such as in-hospital death and intensive care unit (ICU) admission $(7,8)$. However, some studies have found that frailty is not correlated with mortality $(9,10)$. Therefore, it is necessary to synthesize all available evidence to understand whether frailty is a predictor of mortality so as to inform evidencebased decisions in clinical practice. This study provides a systematic review and meta-analysis to compare the mortality risk of frail $v s$. non-frail hospitalized patients with COVID-19. We present the following article in accordance with the MOOSE reporting checklist (available at https:// atm.amegroups.com/article/view/10.21037/atm-22-274/rc).

\section{Methods}

\section{Search strategy}

MEDLINE, Embase, and the Cochrane Library databases were comprehensively searched for relevant studies up to September 11, 2021. The search algorithms consisted of Medical Subject Headings (MeSH) and keywords as follows: "frail" or "frailty" (MeSH) and ("COVID-19" OR "Coronavirus Infection Disease 2019" OR "SARS-CoV-2" OR "Coronavirus Infection") and ("mortality" or "deceased" or "death"). Additionally, we reviewed the reference lists of eligible articles to identify potential gray literature. The complete search strategy is available in Tables S1,S2 .

\section{Eligibility criteria}

Two reviewers (PZ and $\mathrm{MH}$ ) blindly and independently selected the eligible studies if they met the following inclusion criteria: (I) studies that reported the associations between frailty and mortality in hospitalized patients with COVID-19; (II) studies that reported short-term mortality outcomes, i.e., in-hospital mortality, 30-day mortality, or 60 -day mortality. Studies were excluded if they met the following criteria: (I) review articles or letters; (II) studies with less than 20 participants; (III) studies with insufficient data; (IV) non-English language studies. Any differences of opinion between the reviewers regarding an article's qualification for inclusion were resolved by discussion.

\section{Data collection}

The data were extracted by two reviewers (PZ and $\mathrm{MH}$ ) independently, and any differences of opinion were resolved by discussion. Data extracted from the articles included the following: name of the first author, study year, institution(s), number of participating centers, study design, enrollment period, the number of patients, age, gender, frailty assessment tools, and prevalence of frailty. The primary outcome was short-term mortality, defined as a composite outcome of in-hospital mortality, 30-day mortality, or 60-day mortality. The secondary outcome was ICU admission.

\section{Quality assessment}

The methodological quality of the included studies was assessed using the Newcastle-Ottawa scale (NOS) (13). Two reviewers (PZ and $\mathrm{MH}$ ) independently assessed the methodological quality of the included studies. The results of the quality assessment are reported in Table S3.

\section{Statistical analysis}

The effect size (ES) (the exact number of frail patients and mortality) was used to assess the association between frailty and mortality risk in patients with COVID-19. The pooled odds ratio (OR) with $95 \%$ confidence intervals (CIs) were calculated using a random-effects model to compare mortality and ICU admission rates between frail and non-frail patients from the data of the included 


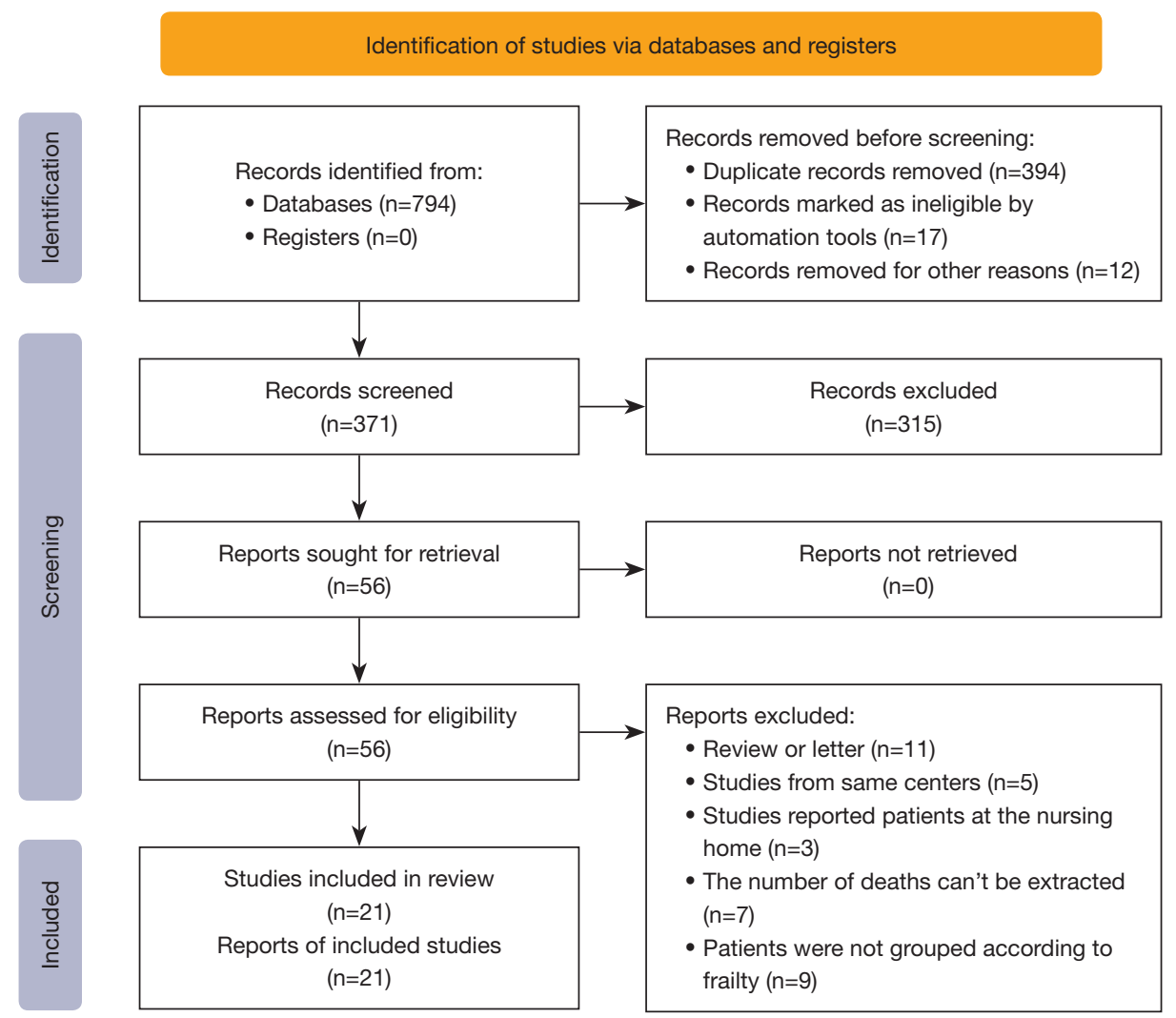

Figure 1 PRISMA flowchart of the study selection process. PRISMA, Preferred Reporting Items for Systematic Reviews and MetaAnalyses.

studies. Heterogeneity between studies was tested using the $\mathrm{I}^{2}$ statistic. The potential publication bias was evaluated quantitatively with Egger's test and assessed qualitatively with funnel plots. Sensitivity analysis was carried out to assess the heterogeneity and robustness of pooled outcomes. We performed subgroup analyses based on the frailty assessment tools. We also demonstrated the outcome estimates for older patients (age $\geq 65$ years). All statistical analyses were carried out using STATA statistical software, version 15.1 (StataCorp., TX, USA). In all analyses, a P value less than 0.05 was considered statistically significant.

\section{Results}

\section{Study selection}

After removing duplicate publications, a total of 371 articles were identified from the electronic database searches. After screening the titles and abstracts, 315 irrelevant articles were removed. Full-text articles were carefully reviewed, and an additional 35 studies were excluded. Eventually, 21 studies meeting the inclusion and exclusion criteria were included in this meta-analysis (7-10,14-29). A PRISMA flow chart of the article selection is shown in Figure 1.

\section{Study characteristics}

Twenty-one included studies, composed of 26,652 hospitalized patients with COVID-19, reported the association between frailty and mortality risk. The principal characteristics of the included studies are reported in Table 1. Over half of the studies included older adults (age $\geq 65$ years), and $50.1 \%(13,187 / 26,303)$ of patients were female. Six frailty assessment tools were used, including the Clinical Frailty Score (CFS) $(n=16)(7-9,11,16-25)$, the Hospital Frailty Risk Score (HFRS) $(n=1)(26)$, the Geriatric Nutritional Risk Index (GRNI) $(\mathrm{n}=1)(27)$, the modified Frailty Index (mFI) $(\mathrm{n}=1)(28)$, the Multidimensional Prognostic Index (MPI) $(n=1)(29)$, and the Frail NonDisabled Survey (FIND) $(\mathrm{n}=1)(10)$. The prevalence of 
Table 1 Characteristics of the studies included in the meta-analysis

\begin{tabular}{|c|c|c|c|c|c|c|c|c|c|c|}
\hline Study & Design & Region & Sample & Consecutive & Female & Age, year ${ }^{\mathrm{a}}$ & $\begin{array}{c}\text { Age } \\
\text { limitation, } \\
\text { year-old }\end{array}$ & $\begin{array}{c}\text { Prevalence of } \\
\text { frailty }\end{array}$ & $\begin{array}{l}\text { Frailty } \\
\text { criteria }\end{array}$ & Outcome measures \\
\hline Owen 2021 & RCS & UK & 206 & NM & NM & NM & $\geq 65$ & $\begin{array}{c}53.9 \% \\
(110 / 206)\end{array}$ & CFS & 30-day mortality \\
\hline $\begin{array}{l}\text { Chinnadurai } \\
2020\end{array}$ & RCS & UK & 215 & 1 & 85 & [36-88] & NM & $\begin{array}{c}51.2 \% \\
(110 / 215)\end{array}$ & CFS & In-hospital mortality \\
\hline Aw 2020 & RCS & UK & 664 & 1 & 305 & NM & $\geq 65$ & $\begin{array}{c}70.8 \% \\
(470 / 664)\end{array}$ & CFS & In-hospital mortality \\
\hline De Smet 2020 & RCS & Belgium & 81 & 1 & 48 & NM & $\geq 65$ & $79.0 \%(64 / 81)$ & CFS & In-hospital mortality \\
\hline Aliberti 2021 & RCS & Brazil & 1,830 & 1 & 769 & $68.7 \pm 10.1$ & $\geq 50$ & $\begin{array}{c}27.0 \% \\
(494 / 1,830)\end{array}$ & CFS & 30-day mortality \\
\hline $\begin{array}{l}\text { Andrés- } \\
\text { Esteban } 2021\end{array}$ & RCS & Spain & 254 & NM & 96 & $62 \pm 7.2$ & $\geq 65$ & $17.3 \%(44 / 254)$ & CFS & In-hospital mortality \\
\hline Dres 2021 & PCS & $\begin{array}{c}\text { France, } \\
\text { Switzerland, } \\
\text { and Belgium }\end{array}$ & 1,085 & NM & 326 & $68.9 \pm 10.9$ & $\geq 70$ & $9.1 \%(99 / 1,085)$ & CFS & 30-day mortality \\
\hline Burns 2020 & RCS & UK & 28 & NM & 13 & $63.5 \pm 10.4$ & NM & $60.7 \%(17 / 28)$ & CFS & In-hospital mortality \\
\hline Tehrani 2021 & RCS & Sweden & 143 & 0 & NM & $68.2 \pm 11.4$ & NM & $49.7 \%(71 / 143)$ & CFS & 60-day mortality \\
\hline Kundi 2020 & RCS & Turkey & 18,234 & NM & 9736 & $74.1 \pm 7.4$ & $\geq 65$ & $\begin{array}{c}68.1 \% \\
(12420 / 18,234)\end{array}$ & HFRS & In-hospital mortality \\
\hline $\begin{array}{l}\text { Recinella } \\
2020\end{array}$ & RCS & Bologna & 109 & 1 & 55 & NM & $\geq 65$ & $72.5 \%(79 / 109)$ & GRNI & In-hospital mortality \\
\hline $\begin{array}{l}\text { Fumagalli } \\
2021\end{array}$ & RCS & Italy & 221 & 1 & 87 & 82 [78-86] & $\geq 75$ & $72.5 \%(79 / 221)$ & $\mathrm{mFI}$ & In-hospital mortality \\
\hline Pilotto 2021 & PCS & Italy & 227 & 1 & 134 & 80.5 [65-99] & $\geq 65$ & $\begin{array}{c}73.6 \% \\
(167 / 227)\end{array}$ & MPI & In-hospital mortality \\
\hline $\begin{array}{l}\text { Steinmeyer } \\
2020\end{array}$ & RCS & France & 94 & NM & 52 & $85.5 \pm 7.5$ & $\geq 65$ & $87.2 \%(82 / 94)$ & FIND & In-hospital mortality \\
\hline
\end{tabular}

${ }^{a}$, data are expressed as mean \pm standard deviation or median [range] or mean or [range]. RCS, retrospective cohort study; PCS, prospective cohort study; CFS, Clinical Frailty Score; NM, not mentioned; HFRS, Hospital Frailty Risk Score; GNRI, Geriatric Nutritional Risk Index; MFI, modified Frailty Index; MPI, Multidimensional Prognostic Index; FIND, Frail Non-Disabled Survey. 


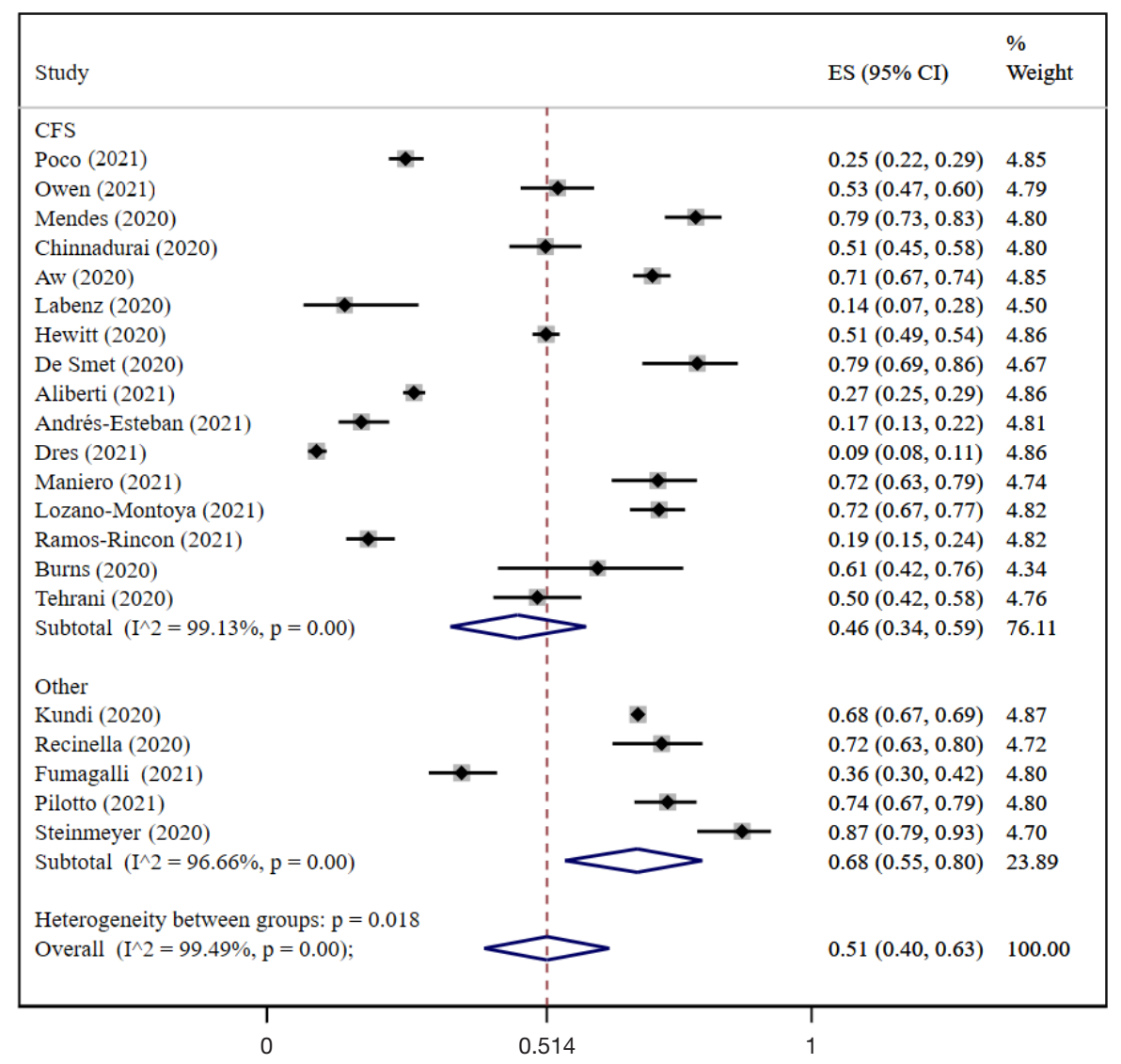

Figure 2 Pooled proportion of frailty in hospitalized patients with COVID-19. COVID-19, coronavirus disease 2019; ES, effect size; CI, confidence interval; CFS, Clinical Frailty Score.

frailty ranged from $9.1-87.2 \%$, with a summary estimate rate of $51.4 \%$ (95\% CI: 39.9-62.9\%; $\mathrm{I}^{2}=99.49 \%$; Figure 2). The result of Egger's test indicated no apparent publication bias $(\mathrm{t}=1.89$; $\mathrm{P}=0.07$; Figure $\mathrm{S} 1)$. The sensitive analysis showed that there was no substantial change on the overall pooled OR (Figure S2).

\section{Association between frailty and short-term mortality}

The short-term mortality outcome measures were inhospital mortality in 17 studies, 30-day mortality in three studies, and 60-day mortality in one study. We performed a subgroup analysis based on the frailty assessment tools used. In the CFS group, frail patients experienced a higher rate of short-term mortality than non-frail patients (OR $=3.0 ; 95 \%$ CI: $2.3-3.9 ; \mathrm{I}^{2}=72.7 \% ; \mathrm{P}<0.001$; Figure 3). In the other tools group (HFRS, GRNI, mFI, MPI, and FIND), frail patients had a significantly higher short-term mortality risk than non-frail patients $\left(\mathrm{OR}=2.4 ; 95 \% \mathrm{CI}\right.$ : $1.4-4.1 ; \mathrm{I}^{2}=63.8 \%$;
$\mathrm{P}=0.001)$. Overall, a higher rate of short-term mortality was observed for frail patients compared with non-frail patients $\left(\mathrm{OR}=2.8 ; 95 \%\right.$ CI: $\left.2.3-3.5 ; \mathrm{I}^{2}=78.0 \% ; \mathrm{P}<0.001\right)$.

The subgroup analysis of older adults (age $\geq 65$ years) revealed that frail patients with COVID-19 in the CFS group had a 2.34-fold higher risk of short-term mortality compared with non-frail patients ( $\mathrm{OR}=2.3$; 95\% CI: $1.7-3.3$; $\mathrm{I}^{2}=62.5 \% ; \mathrm{P}<0.001 ;$ Figure 4$)$. In the other tools group, frail COVID-19 patients experienced a higher rate of short-term mortality than non-frail patients ( $\mathrm{OR}=2.4 ; 95 \% \mathrm{CI}$ : $1.4-4.1$; $\left.\mathrm{I}^{2}=63.8 \% ; \mathrm{P}=0.001\right)$. The overall results revealed that frail patients over 65 years old had significantly increased shortterm mortality compared with non-frail patients $(\mathrm{OR}=2.3$; 95\% CI: $\left.1.8-2.9 ; \mathrm{I}^{2}=60.9 \% ; \mathrm{P}<0.001\right)$.

\section{Association between frailty and ICU admission}

Five studies investigated the association between frailty and ICU admission. Three studies used the CFS, one used the 


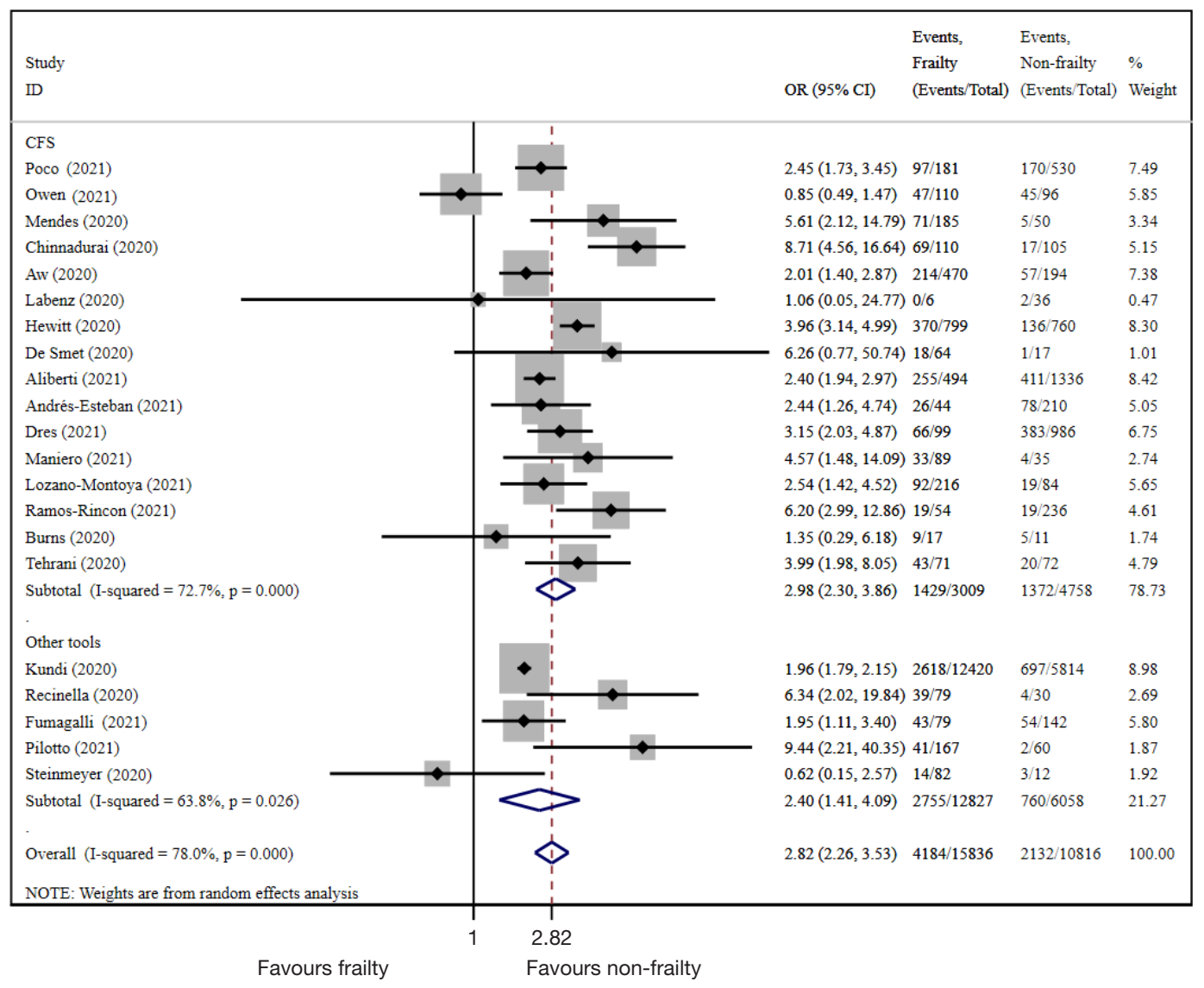

Figure 3 Forest plots of outcomes for short-term mortality in frail vs. non-frail COVID-19 patients. COVID-19, coronavirus disease 2019; OR, odds ratio; CI, confidence interval; CFS, Clinical Frailty Score.

HFRS, and one used the MPI. In the studies using the CFS, the results showed that frail patients had a lower risk of ICU admission than non-frail patients ( $\mathrm{OR}=0.2 ; 95 \%$ CI: $0.1-0.5 ; \mathrm{I}^{2}=0.0 \% ; \mathrm{P}<0.001$; Figure $\left.\mathrm{S} 3\right)$. In contrast, in the other tools group, frail COVID-19 patients demonstrated a higher risk of ICU admission than non-frail patients (OR $=2.0 ; 95 \%$ CI: $\left.1.8-2.1 ; \mathrm{I}^{2}=0.0 \% ; \mathrm{P}<0.001\right)$. The overall results revealed no significant difference in ICU admission rates between frail and non-frail patients $(\mathrm{OR}=0.5 ; 95 \%$ CI: $0.1-2.1 ; \mathrm{I}^{2}=89.4 \% ; \mathrm{P}=0.37$ ).

\section{Discussion}

This systematic review and meta-analysis included 21 studies with 26,652 hospitalized COVID-19 patients and aimed to assess the influence of frailty on clinical outcomes. We pooled the prevalence of frailty and found that over half of COVID-19 patients were frail. CFS was the most commonly used frailty assessment in the studies of hospitalized COVID-19 patients. Frail patients had a higher rate of short-term mortality than non-frail patients, which was also evident in older adults. However, the results from studies investigating ICU admissions that used CFS and other frailty assessment tools were conflicting.

Frailty is a complex age-related clinical state or syndrome characterized by increasing susceptibility to stress, with a functional decline across multiple physiological systems $(30,31)$. COVID-19 caused by SARS-CoV-2 has created a global pandemic and challenged healthcare systems worldwide (1,32). COVID-19 is a systemic disease that can rapidly cause hypoxemic respiratory symptoms and even acute respiratory distress syndrome (ARDS) (33). It is worth mentioning that, compared with computed tomography, lung ultrasound is a non-invasive bedside and low cost technique with high diagnostic accuracy. Lung ultrasound might play an important role in early diagnosis, monitoring of COVID-19 pneumonia, especially in the COVID-19 patients with frailty, which might reduce the pressure 


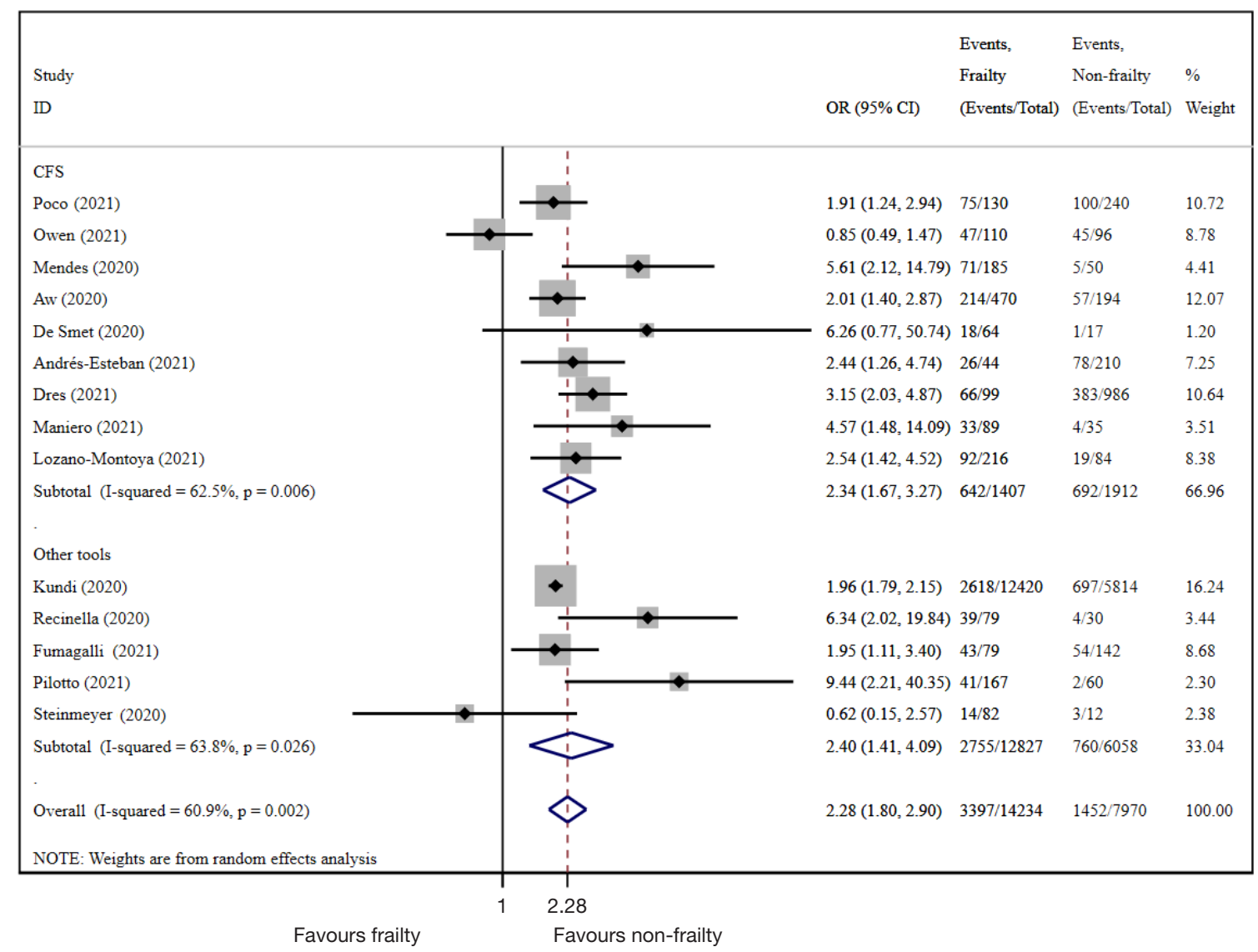

Figure 4 Forest plots of outcomes for short-term mortality in frail $v s$. non-frail COVID-19 patients $\geq 65$ years old. COVID-19, coronavirus disease 2019; OR, odds ratio; CI, confidence interval; CFS, Clinical Frailty Score.

on the patients' body and handling time, and decrease the risk of SARS-CoV-2 transmission (34,35). Besides, based on the blood dissemination of hemophagocytic lymphohistiocytosis, COVID-19 can have secondary effects on extrapulmonary organs, including the nervous system, heart, intestine, kidney, and liver, resulting in multiple organ system dysfunction syndrome (36-38). As a consequence, patients infected with COVID-19 have an increased vulnerability to frailty. Therefore, to improve the prognosis of patients with COVID-19, identifying whether they are frail and need more intensive care is of utmost importance.

There are several well-validated frailty assessment tools used for screening and quantifying frailty status. Many studies across different diseases have revealed that frailty is associated with a variety of poor health outcomes, such as falls, dementia, mortality, hospitalization, and poor quality of life (39-41). As such, it is important to evaluate frailty status comprehensively to optimize outcomes. In this study, we found that frailty was a predictor of all-cause mortality in hospitalized COVID-19 patients, similar to the results of previous systematic reviews. There may be several reasons for this result. First, compared with non-frail patients, patients in a frail condition are characterized by reduced physiological reserves, chronic malnutrition, and a loss of resistance to stressors due to accumulated deficits, all of which increase the risk of a poor outcome for patients infected by SARS-CoV-2 $(42,43)$. Second, frail patients tend to develop a pro-inflammatory status with an elevated level of inflammatory markers in cells and tissues. A leading cause of severe COVID-19 is the cytokine storm syndrome, associated with various cytokines such as IFNa, IL-6, and IL-1, which are elevated in frail patients $(36,37)$. This can lead to immunologic derangement and increase the risk of extrapulmonary organ dysfunction. Third, most frail patients are older adults, and high COVID-19-associated mortality occurs among the older population. This may be due to the high prevalence of comorbidities, such as 
hypertension, diabetes mellitus, chronic heart disease, and dementia in the geriatric population, which have been identified as risk factors for mortality in patients $\geq 65$ years old with COVID-19 (44).

Based on the pooled analysis, we found contradictory results in the association between frailty and ICU admission. According to the results of studies using CFS, frail patients had a lower risk of ICU admission than non-frail patients $(\mathrm{OR}=0.2$; 95\% CI: 0.1-0.5). However, among the studies using other tools, frail patients experienced a higher risk of ICU admission than non-frail patients (OR $=2.0 ; 95 \%$ CI: 1.8-2.1). Dumitrascu et al. (45) reported that eight studies showed an association between frailty as assessed by the CFS and ICU admission (OR $=0.24$; 95\% CI: 0.08-0.71). This discrepancy in results might be caused by the sampling error between studies using the CFS $v s$. other assessment tools and the shortage of medical resources in the early stages of the COVID-19 pandemic. The National Institute for Health and Care Excellence (NICE) guidelines (46) suggest that the CFS should be used to assess whether COVID-19 patients need more intensive care. Based on previous research and the current meta-analysis, further studies are required to confirm this suggestion.

Several limitations of this meta-analysis need to be considered. Firstly, during the study selection, a number of studies reporting the association between frailty and mortality in COVID-19 hospitalized patients were excluded because of non-standard cut-off values for frailty groupings. Furthermore, the effect values of these studies were reported as either ORs or risk ratios. To maximize the pooling of the overall estimates and avoid inflated risk estimates by converting ORs into risk ratios, several studies were excluded where the data could not be extracted. Moreover, most studies were retrospective in design. Therefore, the pooled outcomes were inevitably affected by selection bias. Secondly, because most studies used the CFS as the frailty assessment tool, we conducted a pooled analysis combining the results from other tools used. The data were too limited to allow for further subgroup analysis, which may have decreased the reliability of the results in our meta-analysis.

\section{Conclusions}

The results of this systematic review and meta-analysis indicated that frail patients suffered from a higher risk of all-cause mortality than non-frail hospitalized COVID-19 patients, and this result was also found in the older adult group. Therefore, an assessment of frailty could assist clinicians in identifying hospitalized COVID-19 patients who require more intensive treatment and care.

\section{Acknowledgments}

Funding: This study was supported by the Science and Technology Department of Sichuan Province (Grant No. 2019JY0346) and the National Clinical Research Center for Geriatrics, West China Hospital, Sichuan University (Grant No. Z2018A12).

\section{Footnote}

Reporting Checklist: The authors have completed the MOOSE reporting checklist. Available at https://atm. amegroups.com/article/view/10.21037/atm-22-274/rc

Conflicts of Interest: All authors have completed the ICMJE uniform disclosure form (available at https://atm. amegroups.com/article/view/10.21037/atm-22-274/coif). The authors have no conflicts of interest to declare.

Ethical Statement: The authors are accountable for all aspects of the work in ensuring that questions related to the accuracy or integrity of any part of the work are appropriately investigated and resolved.

Open Access Statement: This is an Open Access article distributed in accordance with the Creative Commons Attribution-NonCommercial-NoDerivs 4.0 International License (CC BY-NC-ND 4.0), which permits the noncommercial replication and distribution of the article with the strict proviso that no changes or edits are made and the original work is properly cited (including links to both the formal publication through the relevant DOI and the license). See: https://creativecommons.org/licenses/by-nc-nd/4.0/.

\section{References}

1. Jefferson T, Spencer EA, Brassey J, et al. Transmission of Severe Acute Respiratory Syndrome Coronavirus-2 (SARS-CoV-2) from pre and asymptomatic infected individuals: a systematic review. Clin Microbiol Infect 2021. [Epub ahead of print]. doi: 10.1016/ j.cmi.2021.10.015.

2. COVID-19 coronavirus pandemic. Available online: https://www.worldometers.info/coronavirus/ 
3. Gacche RN, Gacche RA, Chen J, et al. Predictors of morbidity and mortality in COVID-19. Eur Rev Med Pharmacol Sci 2021;25:1684-707.

4. Mitnitski A, Rockwood K. The rate of aging: the rate of deficit accumulation does not change over the adult life span. Biogerontology 2016;17:199-204.

5. Carneiro JA, Cardoso RR, Durães MS, et al. Frailty in the elderly: prevalence and associated factors. Rev Bras Enferm 2017;70:747-52.

6. Rockwood K, Song X, MacKnight C, et al. A global clinical measure of fitness and frailty in elderly people. CMAJ 2005;173:489-95.

7. Hewitt J, Carter B, Vilches-Moraga A, et al. The effect of frailty on survival in patients with COVID-19 (COPE): a multicentre, European, observational cohort study. Lancet Public Health 2020;5:e444-51.

8. Ramos-Rincon JM, Moreno-Perez O, Pinargote-Celorio H, et al. Clinical Frailty Score vs Hospital Frailty Risk Score for predicting mortality and other adverse outcome in hospitalised patients with COVID-19: Spanish case series. Int J Clin Pract 2021;75:e14599.

9. Owen RK, Conroy SP, Taub N, et al. Comparing associations between frailty and mortality in hospitalised older adults with or without COVID-19 infection: a retrospective observational study using electronic health records. Age Ageing 2021;50:307-16.

10. Steinmeyer Z, Vienne-Noyes S, Bernard M, et al. Acute Care of Older Patients with COVID-19: Clinical Characteristics and Outcomes. Geriatrics (Basel) 2020;5:65.

11. Poco PCE, Aliberti MJR, Dias MB, et al. Divergent: Age, Frailty, and Atypical Presentations of COVID-19 in Hospitalized Patients. J Gerontol A Biol Sci Med Sci 2021;76:e46-51.

12. Ma Y, Hou L, Yang X, et al. The association between frailty and severe disease among COVID-19 patients aged over 60 years in China: a prospective cohort study. BMC Med 2020;18:274.

13. Stang A. Critical evaluation of the Newcastle-Ottawa scale for the assessment of the quality of nonrandomized studies in meta-analyses. Eur J Epidemiol 2010;25:603-5.

14. Mendes A, Serratrice C, Herrmann FR, et al. Predictors of In-Hospital Mortality in Older Patients With COVID-19: The COVIDAge Study. J Am Med Dir Assoc 2020;21:1546-54.e3.

15. Chinnadurai R, Ogedengbe O, Agarwal P, et al. Older age and frailty are the chief predictors of mortality in COVID-19 patients admitted to an acute medical unit in a secondary care setting- a cohort study. BMC Geriatr 2020;20:409.

16. Aw D, Woodrow L, Ogliari G, et al. Association of frailty with mortality in older inpatients with Covid-19: a cohort study. Age Ageing 2020;49:915-22.

17. Labenz C, Kremer WM, Schattenberg JM, et al. Clinical Frailty Scale for risk stratification in patients with SARSCoV-2 infection. J Investig Med 2020;68:1199-202.

18. De Smet R, Mellaerts B, Vandewinckele H, et al. Frailty and Mortality in Hospitalized Older Adults With COVID-19: Retrospective Observational Study. J Am Med Dir Assoc 2020;21:928-32.e1.

19. Andrés-Esteban EM, Quintana-Diaz M, RamírezCervantes KL, et al. Outcomes of hospitalized patients with COVID-19 according to level of frailty. PeerJ 2021;9:e11260.

20. Aliberti MJR, Szlejf C, Avelino-Silva VI, et al. COVID-19 is not over and age is not enough: Using frailty for prognostication in hospitalized patients. J Am Geriatr Soc 2021;69:1116-27.

21. Dres M, Hajage D, Lebbah S, et al. Characteristics, management, and prognosis of elderly patients with COVID-19 admitted in the ICU during the first wave: insights from the COVID-ICU study : Prognosis of COVID-19 elderly critically ill patients in the ICU. Ann Intensive Care 2021;11:77.

22. Maniero C, Patel D, Pavithran A, et al. A retrospective cohort study of risk factors and outcomes in older patients admitted to an inner-city geriatric unit in London during first peak of COVID-19 pandemic. Ir J Med Sci 2021. [Epub ahead of print]. doi: 10.1007/s11845-021-02679-z.

23. Lozano-Montoya I, Quezada-Feijoo M, Jaramillo-Hidalgo $\mathrm{J}$, et al. Mortality risk factors in a Spanish cohort of oldestold patients hospitalized with COVID-19 in an acute geriatric unit: the OCTA-COVID study. Eur Geriatr Med 2021;12:1169-80.

24. Burns GP, Lane ND, Tedd HM, et al. Improved survival following ward-based non-invasive pressure support for severe hypoxia in a cohort of frail patients with COVID-19: retrospective analysis from a UK teaching hospital. BMJ Open Respir Res 2020;7:e000621.

25. Tehrani S, Killander A, Åstrand P, et al. Risk factors for death in adult COVID-19 patients: Frailty predicts fatal outcome in older patients. Int J Infect Dis 2021;102:415-21.

26. Kundi H, Çetin EHÖ, Canpolat U, et al. The role of Frailty on Adverse Outcomes Among Older Patients with COVID-19. J Infect 2020;81:944-51.

27. Recinella G, Marasco G, Serafini G, et al. Prognostic role 


\section{Page 10 of 10}

of nutritional status in elderly patients hospitalized for COVID-19: a monocentric study. Aging Clin Exp Res 2020;32:2695-701.

28. Fumagalli C, Ungar A, Rozzini R, et al. Predicting Mortality Risk in Older Hospitalized Persons With COVID-19: A Comparison of the COVID-19 Mortality Risk Score with Frailty and Disability. J Am Med Dir Assoc 2021;22:1588-92.e1.

29. Pilotto A, Azzini M, Cella A, et al. The multidimensional prognostic index (MPI) for the prognostic stratification of older inpatients with COVID-19: A multicenter prospective observational cohort study. Arch Gerontol Geriatr 2021;95:104415.

30. Clegg A, Young J, Iliffe S, et al. Frailty in elderly people. Lancet 2013;381:752-62.

31. Kojima G. Frailty as a predictor of hospitalisation among community-dwelling older people: a systematic review and meta-analysis. J Epidemiol Community Health 2016;70:722-9.

32. Rothan HA, Byrareddy SN. The epidemiology and pathogenesis of coronavirus disease (COVID-19) outbreak. J Autoimmun 2020;109:102433.

33. Yang X, Yu Y, Xu J, et al. Clinical course and outcomes of critically ill patients with SARS-CoV-2 pneumonia in Wuhan, China: a single-centered, retrospective, observational study. Lancet Respir Med 2020;8:475-81.

34. Allinovi M, Parise A, Giacalone $M$, et al. Lung Ultrasound May Support Diagnosis and Monitoring of COVID-19 Pneumonia. Ultrasound Med Biol 2020;46:2908-17.

35. Smith MJ, Hayward SA, Innes SM, et al. Point-of-care lung ultrasound in patients with COVID-19 - a narrative review. Anaesthesia 2020;75:1096-104.

36. Mehta P, McAuley DF, Brown M, et al. COVID-19: consider cytokine storm syndromes and immunosuppression. Lancet 2020;395:1033-4.

37. Kim JS, Lee JY, Yang JW, et al. Immunopathogenesis and treatment of cytokine storm in COVID-19. Theranostics
2021;11:316-29.

38. Ferrucci L, Fabbri E. Inflammageing: chronic inflammation in ageing, cardiovascular disease, and frailty. Nat Rev Cardiol 2018;15:505-22.

39. Qiu Y, Li G, Wang X, et al. Prevalence of cognitive frailty among community-dwelling older adults: A systematic review and meta-analysis. Int J Nurs Stud 2022;125:104112.

40. Brown PJ, Ciarleglio A, Roose SP, et al. Frailty and Depression in Late Life: A High-Risk Comorbidity with Distinctive Clinical Presentation and Poor Antidepressant Response. J Gerontol A Biol Sci Med Sci 2021. [Epub ahead of print]. doi: 10.1093/gerona/glab338.

41. Gracie TJ, Caufield-Noll C, Wang NY, et al. The Association of Preoperative Frailty and Postoperative Delirium: A Meta-analysis. Anesth Analg 2021;133:314-23.

42. Moraes MB, Avgerinou C, Fukushima FB, et al. Nutritional interventions for the management of frailty in older adults: systematic review and meta-analysis of randomized clinical trials. Nutr Rev 2021;79:889-913.

43. El Assar M, Angulo J, Carnicero JA, et al. Association between telomere length, frailty and death in older adults. Geroscience 2021;43:1015-27.

44. Kojima G, Iliffe S, Walters K. Frailty index as a predictor of mortality: a systematic review and meta-analysis. Age Ageing 2018;47:193-200.

45. Dumitrascu F, Branje KE, Hladkowicz ES, et al. Association of frailty with outcomes in individuals with COVID-19: A living review and meta-analysis. J Am Geriatr Soc 2021;69:2419-29.

46. National Institute for Health and Care Excellence. COVID-19 Rapid Guideline: Critical Care in Adults. London: National Institute for Health and Care Excellence, 2020. Available online: https://www.nice.org. uk/guidance/ng159

(English Language Editor: D. Fitzgerald)
Cite this article as: Zou Y, Han M, Wang J, Zhao J, Gan H, Yang Y. Predictive value of frailty in the mortality of hospitalized patients with COVID-19: a systematic review and meta-analysis. Ann Transl Med 2022;10(4):166. doi: 10.21037/atm-22-274 
Supplementary

Table S1 Search strategies of MEDLINE*

\begin{tabular}{llc}
\hline Searches & Details & Results \\
\hline 1 & frail.mp. or Frailty/ & 23,464 \\
2 & $\begin{array}{l}\text { Coronavirus Infections/or novel } \\
\text { coronavirus.mp. }\end{array}$ & 51,954 \\
3 & SARS-CoV-2/or COVID-19/or Coronavirus & 113,435 \\
& Infection Disease 2019.mp. & \\
4 & Mortality/or mortality.mp. & $1,262,840$ \\
5 & death.mp. or Death/ & 874,408 \\
6 & deceased.mp. & 22,590 \\
7 & 2 or 3 & 122,675 \\
8 & 4 or 5 or 6 & $1,907,321$ \\
9 & 1 and 7 and 8 & 346 \\
\hline
\end{tabular}

*, Ovid MEDLINE(R) and Epub Ahead of Print, In-Process \& Other Non-Indexed Citations, Daily and Versions (R) 1946 to September 11, 2021.
Table S2 Search strategies of Embase*

\begin{tabular}{|c|c|c|}
\hline Searches & Details & Results \\
\hline 1 & frailty/or frail elderly/or frail.mp. & 38,414 \\
\hline 2 & $\begin{array}{l}\text { coronavirus disease 2019/or COVID-19/or } \\
\text { Coronavirus Infection Disease 2019.mp. }\end{array}$ & 154,839 \\
\hline 3 & $\begin{array}{l}\text { SARS-CoV-2.mp. or Severe acute } \\
\text { respiratory syndrome coronavirus 2/ }\end{array}$ & 77,470 \\
\hline 4 & $\begin{array}{l}\text { Coronavirus infection/or novel coronavirus. } \\
\mathrm{mp} .\end{array}$ & 21,630 \\
\hline 5 & Mortality/or mortality.mp. & $1,642,475$ \\
\hline 6 & death.mp. or Death/ & $1,379,172$ \\
\hline 7 & deceased.mp. & 43,982 \\
\hline 8 & 2 or 3 or 4 & 182,980 \\
\hline 9 & 5 or 6 or 7 & $2,690,210$ \\
\hline 10 & 1 or 8 or 9 & 448 \\
\hline
\end{tabular}

*, Embase 1974 to September 11, 2021. 
Table S3 NOS quality assessment results of the cohort studies

\begin{tabular}{|c|c|c|c|c|c|c|c|c|c|c|}
\hline Author & Year & $\begin{array}{l}\text { Representativeness } \\
\text { of the exposed } \\
\text { cohort }\end{array}$ & $\begin{array}{l}\text { Selection of the } \\
\text { nonexposed } \\
\text { cohort }\end{array}$ & $\begin{array}{l}\text { Ascertainment } \\
\text { of exposure }\end{array}$ & $\begin{array}{c}\text { Outcome of interest } \\
\text { was not present at } \\
\text { start of study }\end{array}$ & $\begin{array}{l}\text { Comparability of } \\
\text { cohorts on the basis of } \\
\text { the design or analysis }\end{array}$ & $\begin{array}{c}\text { Assessment of } \\
\text { outcome }\end{array}$ & $\begin{array}{l}\text { Was follow-up long } \\
\text { enough for outcomes to } \\
\text { occur }\end{array}$ & $\begin{array}{l}\text { Adequacy of } \\
\text { follow-up of } \\
\text { cohorts }\end{array}$ & $\begin{array}{l}\text { Total } \\
\text { score }\end{array}$ \\
\hline Poco & 2021 & 1 & 1 & 1 & 1 & 1 & 1 & 1 & 1 & 8 \\
\hline Owen & 2021 & 1 & 1 & 1 & 1 & 1 & 1 & 1 & 1 & 8 \\
\hline Mendes & 2020 & 1 & 1 & 1 & 1 & 1 & 1 & 1 & 1 & 8 \\
\hline Chinnadurai & 2020 & 1 & 1 & 1 & 1 & 1 & 1 & 1 & 1 & 8 \\
\hline Aw & 2020 & 1 & 1 & 1 & 1 & 1 & 1 & 0 & 1 & 7 \\
\hline Labenz & 2020 & 1 & 1 & 1 & 1 & 0 & 1 & 1 & 1 & 7 \\
\hline Hewitt & 2020 & 1 & 1 & 1 & 1 & 1 & 1 & 1 & 1 & 8 \\
\hline De Smet & 2020 & 1 & 1 & 1 & 1 & 1 & 1 & 1 & 1 & 8 \\
\hline Aliberti & 2021 & 1 & 1 & 1 & 1 & 1 & 1 & 1 & 1 & 8 \\
\hline Andrés-Esteban & 2021 & 1 & 1 & 1 & 1 & 1 & 1 & 1 & 1 & 8 \\
\hline Dres & 2021 & 1 & 1 & 1 & 1 & 1 & 1 & 1 & 1 & 8 \\
\hline Maniero & 2021 & 1 & 1 & 1 & 1 & 0 & 1 & 1 & 1 & 7 \\
\hline Lozano-Montoya & 2021 & 1 & 1 & 1 & 1 & 1 & 1 & 1 & 1 & 8 \\
\hline Ramos-Rincon & 2021 & 1 & 1 & 1 & 1 & 1 & 1 & 1 & 1 & 8 \\
\hline Burns & 2020 & 1 & 1 & 1 & 1 & 0 & 1 & 1 & 1 & 7 \\
\hline Tehrani & 2021 & 1 & 1 & 1 & 1 & 1 & 1 & 1 & 1 & 8 \\
\hline Kundi & 2020 & 1 & 1 & 1 & 1 & 1 & 1 & 1 & 1 & 8 \\
\hline Recinella & 2020 & 1 & 1 & 1 & 1 & 1 & 1 & 1 & 1 & 8 \\
\hline Fumagalli & 2021 & 1 & 1 & 1 & 1 & 1 & 1 & 1 & 1 & 8 \\
\hline Pilotto & 2021 & 1 & 1 & 1 & 1 & 1 & 1 & 1 & 1 & 8 \\
\hline Steinmeyer & 2020 & 1 & 1 & 1 & 1 & 0 & 1 & 1 & 1 & 7 \\
\hline
\end{tabular}

NOS, Newcastle-Ottawa scale. 


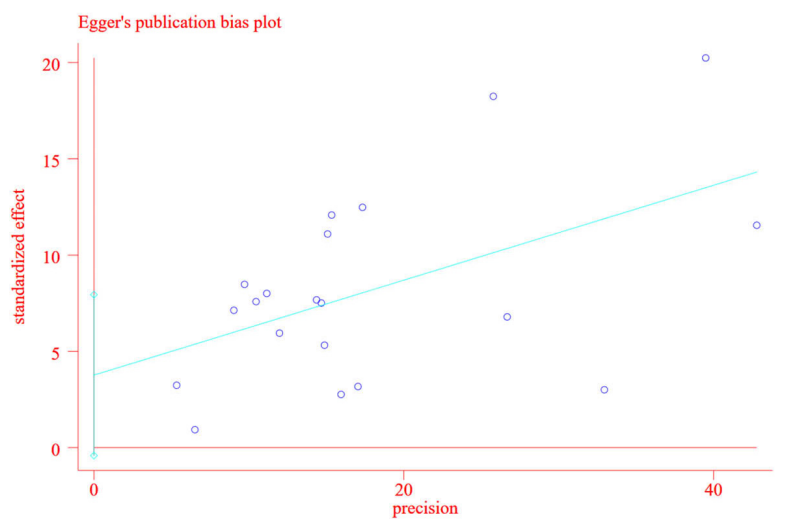

Figure S1 Egger's test for publication bias.

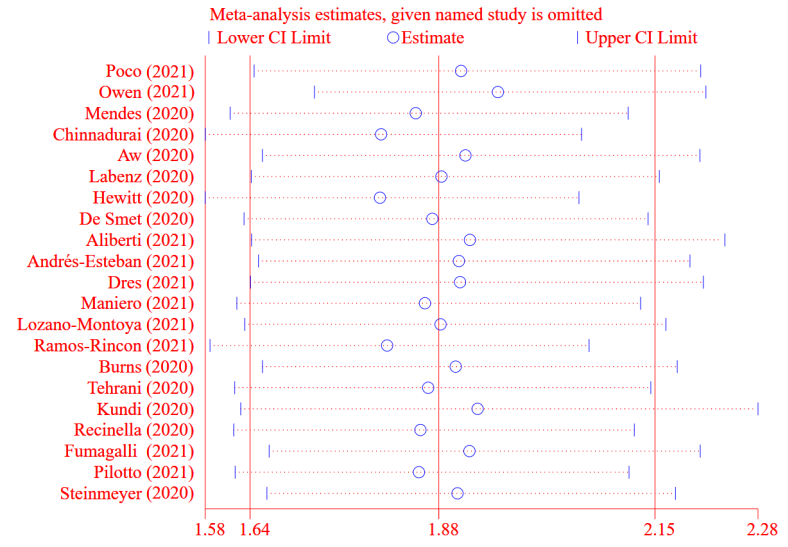

Figure S2 Sensitivity analysis for the association between frailty and short-term mortality of hospitalized patients with COVID-19. COVID-19, coronavirus disease 2019; CI, confidence interval.

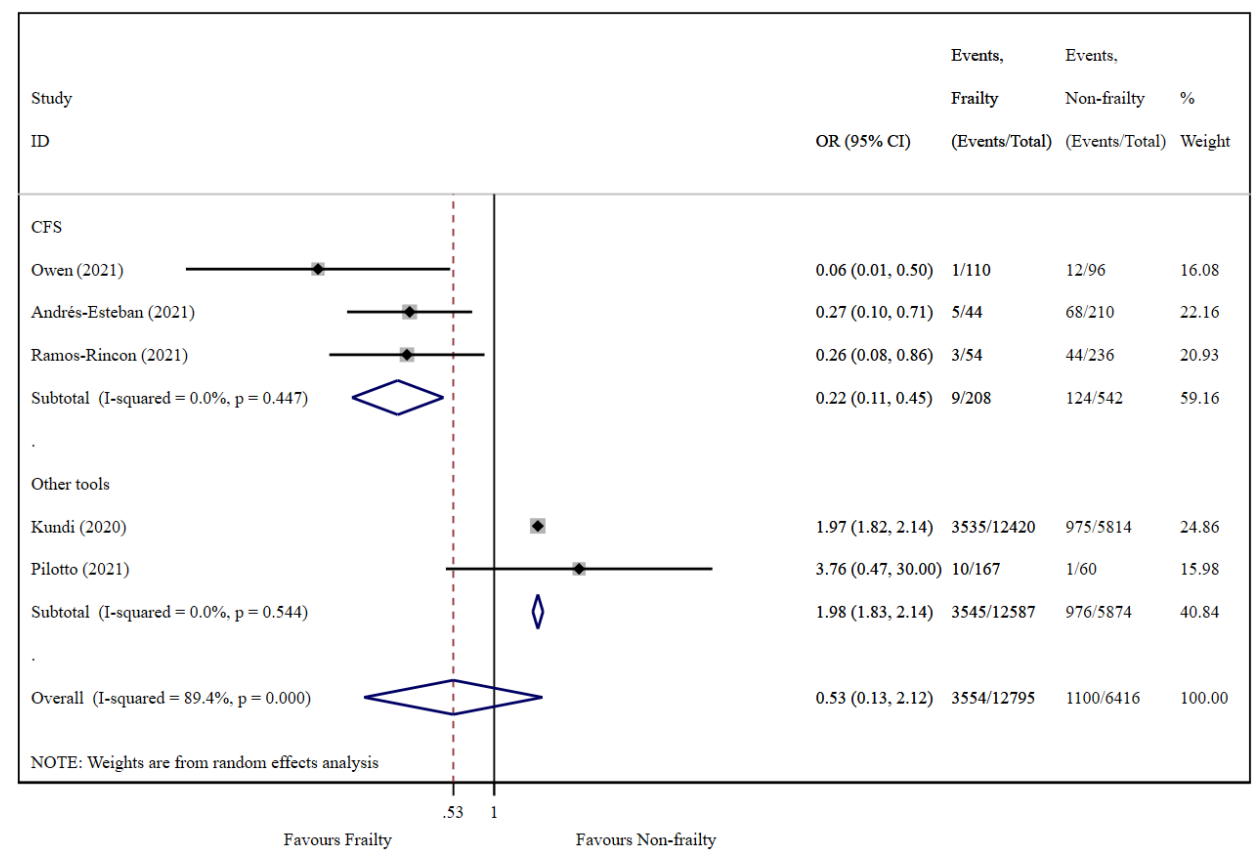

Figure S3 Forest plots of outcomes for ICU admission in frail vs. non-frail COVID-19 patients. ICU, intensive care unit; COVID-19, coronavirus disease 2019; OR, odds ratio; CI, confidence interval; CFS, Clinical Frailty Score. 